\title{
Hypothalamic-pituitary-adrenal axis and behavioral dysfunction following early binge-like prenatal alcohol exposure in mice
}

\author{
Lindsay Wieczorek ${ }^{1,{ }^{*}}$, Eric W. Fish ${ }^{1}$, Shonagh K. O’Leary-Moore ${ }^{1,2}$, Scott E. Parnell ${ }^{1,3,4}$, and \\ Kathleen K. Sulik ${ }^{1,3,4}$ \\ Lindsay Wieczorek: lawieczo@med.unc.edu; Eric W. Fish: efish@med.unc.edu; Shonagh K. O'Leary-Moore: \\ shonagh.moore@gmail.com; Scott E. Parnell: sparnell@med.unc.edu; Kathleen K. Sulik: mouse@med.unc.edu \\ ${ }^{1}$ Bowles Center for Alcohol Studies, University of North Carolina, Chapel Hill, NC, USA \\ ${ }^{2}$ Department of Psychiatry, University of North Carolina, Chapel Hill, NC, USA \\ ${ }^{3}$ Carolina Institute for Developmental Disabilities, University of North Carolina, Chapel Hill, NC, \\ USA \\ ${ }^{4}$ Department of Cell Biology and Physiology, University of North Carolina, Chapel Hill, NC, USA
}

\begin{abstract}
The range of defects that fall within fetal alcohol spectrum disorder (FASD) includes persistent behavioral problems, with anxiety and depression being two of the more commonly reported issues. Previous studies of rodent FASD models suggest that interference with hypothalamicpituitary-adrenal (HPA) axis structure and/or function may be the basis for some of the prenatal alcohol (ethanol) exposure (PAE)-induced behavioral abnormalities. Included among the previous investigations are those illustrating that maternal alcohol treatment limited to very early stages of pregnancy (i.e., gestational day [GD]7 in mice; equivalent to the third week post-fertilization in humans) can cause structural abnormalities in areas such as the hypothalamus, pituitary gland, and other forebrain regions integral to controlling stress and behavioral responses. The current investigation was designed to further examine the sequelae of prenatal alcohol insult at this early time period, with particular attention to HPA axis-associated functional changes in adult mice. The results of this study reveal that GD7 PAE in mice causes HPA axis dysfunction, with males and females showing elevated corticosterone (CORT) and adrenocorticotropic hormone (ACTH) levels, respectively, following a 15-min restraint stress exposure. Males also showed elevated CORT levels following an acute alcohol injection of $2.0 \mathrm{~g} / \mathrm{kg}$, while females displayed blunted ACTH levels. Furthermore, analysis showed that anxiety-like behavior was decreased after GD7 PAE in female mice, but was increased in male mice. Collectively, the results of this study show that early gestational alcohol exposure in mice alters long-term HPA axis activity and behavior in a sexually dimorphic manner.
\end{abstract}

(C) 2015 Elsevier Inc. All rights reserved.

*Corresponding author: Lindsay Wieczorek, 3017 Thurston Bowles Building, Campus Box \#7178, Chapel Hill, NC 27599, Telephone: +1919966 3208, Fax: +1 919966 5679, lawieczo@med.unc.edu.

The authors have no financial or other conflicts of interest.

Publisher's Disclaimer: This is a PDF file of an unedited manuscript that has been accepted for publication. As a service to our customers we are providing this early version of the manuscript. The manuscript will undergo copyediting, typesetting, and review of the resulting proof before it is published in its final citable form. Please note that during the production process errors may be discovered which could affect the content, and all legal disclaimers that apply to the journal pertain. 


\section{Keywords}

hypothalamic-pituitary-adrenal axis; FASD; stress; prenatal alcohol exposure; anxiety; depression

\section{Introduction}

Alcohol use during pregnancy is one of the leading known causes of birth defects (Riley, Infante, \& Warren, 2011), and therefore, represents a major health concern. Current estimates on the prevalence of Fetal Alcohol Syndrome (FAS) in the United States' general population range from 0.2 to 7 per 1,000 live births (May et al., 2009). FAS is characterized by clear morphological changes and functional deficits, and represents the extreme end of the spectrum that can result from prenatal alcohol exposure (PAE). A recent addition to DSM-5, Neurobehavioral Disorder Associated with Prenatal Alcohol Exposure (ND-PAE), encompasses many of the same functional deficits but can be diagnosed in the absence or presence of any physical abnormalities. Both fall within Fetal Alcohol Spectrum Disorder (FASD), an umbrella term that describes the full spectrum of deficits that can occur following PAE, which has a prevalence of 2-5\% in the United States (May et al., 2009). Based on longitudinal studies, an alarming proportion of individuals who are exposed prenatally to alcohol develop a range of mental health disturbances, with several studies finding the prevalence to be $90 \%$ or greater (Rasmussen, Andrew, Zwaigenbaum, \& Tough, 2008; Streissguth, Barr, Kogan, \& Bookstein, 1996). Anxiety and depression, the more common of these problems, occur at higher rates than those found in the general population; rates of occurrence in prenatal alcohol-exposed individuals compared to the general population are $29 \%$ vs. $17 \%$ for anxiety (Barr et al., 2006; Somers, Goldner, Waraich, \& Hsu, 2006) and 52\% vs. $21 \%$ for depression (Cryan, Markou, \& Lucki, 2002; Streissguth et al., 1996). The behavioral abnormalities in FASD are typically apparent in childhood (Fryer, McGee, Matt, Riley, \& Mattson, 2007; O'Connor \& Kasari, 2000; O'Connor et al., 2002; Steinhausen, Willms, Metzke, \& Spohr, 2003) and often persist into adulthood (Barr et al., 2006; Famy, Streissguth, \& Unis, 1998).

Of particular interest for the current study is the association of anxiety and depression with altered hypothalamic-pituitary-adrenal (HPA) axis activity (Burke, Davis, Otte, \& Mohr, 2005; Nemeroff et al., 1984; Vreeburg et al., 2009; Wingenfeld \& Wolf, 2011; Young, Abelson, \& Cameron, 2004). Notably, the literature suggests that normalization of HPA axis dysregulation is a prerequisite for successful and persistent remission of these behavioral problems (Appelhof et al., 2006; Schüle, Baghai, Eser, \& Rupprecht, 2009; Zobel et al., 2001). Overall, HPA axis dysfunction can be a risk factor for HPA axis-related pathologies such as depression, anxiety, and alcoholism, particularly when it has been induced by early life adversity (De Bellis, 2002; Gordon, 2002; Macrì, Spinelli, Adriani, Dee Higley, \& Laviola, 2007). Direct clinical evidence of PAE-mediated alterations in the HPA axis has been reported with infants as young as 5 months showing increased cortisol responsiveness to stress (Haley, Handmaker, \& Lowe, 2006; Jacobson, Bihun, \& Chiodo, 1999). Thus, these HPA axis-associated consequences present early in life may contribute to the increase in later life mental health issues. 
Not only do clinical studies show functional deficits, they also reveal structural deficiencies in the pituitary or hypothalamus after PAE. An investigation directly examining morphological consequences of PAE showed abnormal development of the hypothalamus of both fetuses and children (Peiffer, Majewski, Fischbach, Bierich, \& Volk, 1979). While the exact period of alcohol exposure in the previous study is unknown, an anatomical report looking at a 2.5-month-old girl exposed to first-trimester maternal binge alcohol abuse showed absence of the posterior pituitary, an enlarged and bulbous hypothalamus, and pituitary hormone deficiency (Coulter, Leech, Schaefer, Scheithauer, \& Brumback, 1993). To date, such clinical research has mainly focused on heavy alcohol exposure for extended periods of time, leaving it unclear whether exposures that are more limited can lead to HPA axis dysfunction along with increased anxiety or depression.

While human research cannot readily delineate critical alcohol exposure times or the pattern and amount of maternal alcohol consumption necessary for structural and functional teratogenesis, animal models have proven invaluable in this regard. As seen in clinical studies, animal research employing models with low to moderate alcohol exposure throughout gestation suggests that even low levels of PAE lead to HPA dysfunction, which in turn contributes to behavioral abnormalities. Exemplary are reports describing the impact of PAE on fetal programming of the HPA axis response to stressors (Hellemans, Sliwowska, Verma, \& Weinberg, 2010; Kim, Turnbull, Lee, \& Rivier, 1999; Ogilvie \& Rivier, 1997; Weinberg, Sliwowska, Lan, \& Hellemans, 2008; Weinberg, Taylor, \& Gianoulakis, 1996). Both rodents (Kim, Giberson, Yu, Zoeller, \& Weinberg, 1999; Lee, Imaki, Vale, \& Rivier, 1990; Nelson et al., 1986; Taylor, Branch, Liu, \& Kokka, 1982; Weinberg, 1992) and primates (Schneider, Moore, Kraemer, Roberts, \& DeJesus, 2002) exposed prenatally to alcohol display enhanced HPA axis reactivity to multiple types of stressors, including morphine administration, restraint stress, footshock, cardiac puncture, and cold stress. Furthermore, an overall increase in depression-like symptoms as measured on the forced swim task (Carneiro et al., 2005; Hellemans, Verma, et al., 2010; Wilcoxon, Kuo, Disterhoft, \& Redei, 2005) and anxiety-like behavior as measured on the elevated plus maze (Carneiro et al., 2005; Dursun, Jakubowska-Doğru, \& Uzbay, 2006; Liang et al., 2014) was found in rats. These changes in anxiety-like behavior can be directly linked to changes in HPA axis activity, as evidenced by increased corticosterone (CORT) levels after testing on the elevated plus maze or open field in prenatal alcohol-exposed females, but not males (Hellemans, Verma, Yoon, Yu, \& Weinberg, 2008; Osborn, Kim, Steiger, \& Weinberg, 1998). Importantly, the above findings highlight a role for sex in influencing alcohol's teratogenic outcome and illustrate the importance of study designs that analyze both sexes.

The PAE animal models described above suggest consistent functional changes with alcohol exposure throughout gestation. However, acute, binge-like exposures have the advantage of targeting critical and precisely timed developmental events. This is especially important early in gestation, when developmental changes occur rapidly. Strongly supporting the potential of early, binge-like gestational insult to adversely affect the HPA axis are morphological studies showing that PAE limited to gestational day (GD)7 in mice (developmentally equivalent to the mid-third week post-fertilization in humans) can result in structural abnormalities of the pituitary gland as well as third ventricular enlargement, the 
latter of which may reflect hypothalamic deficiency (Godin et al., 2010; Lipinski et al., 2012).

The current study expands upon this previous anatomical work following an early gestational, binge-like exposure in mice to assess the functional deficits that occur at this period. The hypothesis tested was that early PAE would have lasting consequences on the sensitivity and activity of the HPA axis, that these would alter the expression of behaviors related to anxiety and depression, and that males and females would differ in both of these physiological and behavioral measurements. For this purpose, HPA axis activity was measured by CORT and adrenocorticotropic hormone (ACTH) levels following exposure to two differing stressors (restraint and alcohol injection), and affective behavior was measured in the elevated plus maze, light-dark chamber, and forced swim test.

\section{Methods}

\section{Animal care and prenatal alcohol treatment}

C57B1/6J mice were purchased from The Jackson Laboratory (Bar Harbor, ME) and housed on a 12-h/12-h light/dark cycle (lights on at 7:00 AM) with ad libitum access to standard rodent chow (Isopro RMH 3000; Purina, St. Louis, MO) and water. Timed pregnancies were established by housing two female mice with one male mouse for a period of 1-2 h. GD0, 0 hour, was defined as the beginning of the breeding period in which a copulation plug was detected. Pregnant dams were administered two intra-peritoneal (i.p.) injections of $25 \%$ (v/v) ethanol in a vehicle of lactated Ringer's solution (offspring defined as GD7 Alc) at a dosage of $2.9 \mathrm{~g} / \mathrm{kg}$, given $4 \mathrm{~h}$ apart starting on GD7, 0 hour. Control mice were injected similarly with vehicle alone (offspring defined as GD7 Con) to control for the stress of injection. Blood alcohol concentrations resulting from this PAE procedure have been previously reported, with the peak reaching approximately $420 \mathrm{mg} / \mathrm{dL} 30 \mathrm{~min}$ after the second alcohol injection (Godin et al., 2010; Kotch \& Sulik, 1992).

A total of 102 litters were used for all the experiments. An approximately equal proportion of GD7 Con and GD7 Alc litters were used for all experiments. Litters were culled to a maximum of 8 pups. There were no significant differences in litter size (average size approximately 6 pups/litter) or the number of pups that survived into adulthood between those that were alcohol- or vehicle-treated. All offspring, both male and female, were weaned at $28( \pm 1)$ days and used at 2-4 months for the studies outlined below. The unit of determination for each study was the number of individual mice. For the HPA axis experiments, 1-2 mice/litter/sex were randomly assigned to each time point. For the behavioral experiments, 1-2 mice/litter/sex were randomly assigned to either the anxiety or depression tests. All experiments were conducted between 8:30 AM-1:00 PM. The experiments were in accordance with National Institutes of Health guidelines and approved by the Animal Care and Use Committee at the University of North Carolina at Chapel Hill.

\section{Stress Procedures}

Restraint stress and blood collection-Mice were subjected to 5 or $15 \mathrm{~min}$ of restraint stress using a plastic cone with openings at both ends to allow sufficient airflow 
during restraint (Decapicone; Braintree Scientific, Inc., Braintree, MA). Following restraint, trunk blood was collected for subsequent hormonal analyses. So that all hormone levels were measured at the same time relative to the initiation of restraint, blood was taken $10 \mathrm{~min}$ after the end of the 5-min restraint and immediately following the 15-min restraint. Trunk blood was also collected in separate mice 60 or 90 min after the end of the 15-min restraint period. For control samples, trunk blood was collected from mice that were undisturbed until blood collection. Baseline samples collected during both stress procedures (restraint and alcohol injection) were combined for analysis. Litter total $=31$; male $(n ' s)=$ baseline $(13-$ 17), $5 \mathrm{~min}$ (7-11), $15 \mathrm{~min}$ (4-7), $60 \mathrm{~min}(4-7), 90 \mathrm{~min}(3-6)$; female ( $n$ 's) = baseline (1217), 5 min (7-9), $15 \min (5-7), 60 \min (5-7), 90 \min (4-7)$.

Acute alcohol injection and blood alcohol concentration measurements-Mice were administered an i.p. injection of $25 \%$ (v/v) ethanol in lactated Ringer's solution at a dosage of $2.0 \mathrm{~g} / \mathrm{kg}$. Trunk blood was collected 20,60, or $120 \mathrm{~min}$ after injection for hormone and blood alcohol concentration (BAC) analysis. BACs were determined from plasma samples using an Analox Alcohol Analyzer (Model AM1; Analox Instruments USA, Inc., Lunenburg, MA). Litter total = 35; male ( $n$ 's $)=20 \min (7-8), 60 \min (4-6), 90 \min (6-$ 8); female ( $n$ 's) = $20 \min (6-7), 60 \min (7-8), 90 \min (8)$.

Radioimmunoassay-From the blood collected for both stress procedures, $\mathrm{I}^{125}$ radioimmunoassay kits (MP Biomedicals, Costa Mesa, CA) were used to measure CORT and ACTH levels. Total binding was determined in the absence of unlabeled CORT or $\mathrm{ACTH}$, and non-specific binding was determined in the absence of antibody. Steroid levels in the samples were extrapolated from the standard curve generated during each run.

\section{Behavioral Tests}

Mice were assigned to either the anxiety or the depression tests. Mice assigned to the anxiety tests underwent the elevated plus maze testing followed approximately one week later by light-dark testing. Mice assigned to the depression test underwent a forced swim test.

Light-dark testing-A light-dark chamber using a photocell-equipped automated open field $(41 \mathrm{~cm} \times 41 \mathrm{~cm} \times 30 \mathrm{~cm}$; Versamax System; Accuscan Instruments, Columbus, $\mathrm{OH})$ with an insert used to form the dark side of the chamber was employed. Mice were placed in the light side of the chamber and allowed to freely move between the light and dark side for $10 \mathrm{~min}$. Light exploration was measured via number of entries, time, and distance traveled on the light side of the chamber. Data were automatically recorded and analyzed with VersaMap (Versamax System; Accuscan Instruments, Columbus, $\mathrm{OH}$ ). The number of light entries, light time, and percent light distance traveled ([light distance/(light + dark distance)] $\times 100)$ are reported in the Results section. Litter total $=18$; male $n$ 's $=8-9$; female $n$ 's $=9$ 12.

Elevated plus maze-A metal plus maze with two closed arms (wall height: $20 \mathrm{~cm}$ ) and two open arms (length: $30 \mathrm{~cm}$ ) was used. The maze was elevated $50 \mathrm{~cm}$ from the floor. Mice were placed on the center section and allowed to freely explore for $5 \mathrm{~min}$. Entries and time 
in each arm were manually recorded during the trial by two observers who were blind to prenatal treatment. Number of entries and percent time in the open arms ([open arms time/ (closed + open arms time) $] \times 100$ ) are reported in the Results section. Litter total and $n$ 's are the same as the light-dark testing, as above.

Forced swim test-Mice were placed into a 4-L Pyrex ${ }^{\circledR}$ beaker containing $3 \mathrm{~L}$ of 23-26 ${ }^{\circ} \mathrm{C}$ tap water for a period of $6 \mathrm{~min}$. The total distance traveled and duration of immobility were scored using Ethovision 7 (Noldus Information Technology, Leesburg, VA) with an immobility threshold of $6 \%$. Litter total $=18$; male $n$ 's $=10-11$; female $n$ 's $=13-15$.

\section{Statistical analyses}

Results are expressed as the mean \pm SEM. The HPA axis data were analyzed with a twoway ANOVA (prenatal treatment $\times$ time), while the data for light-dark testing and forced swim testing were analyzed per minute bins with a two-way repeated-measures ANOVA (prenatal treatment $\times$ time). Post hoc analyses were performed using Bonferroni post hoc tests when $F$ tests revealed significance at $p \leq 0.05$. The data for the elevated plus maze were analyzed over the entire test with unpaired, two-tailed Student's $t$ tests. To explore the relationship between CORT or ACTH levels and BACs, Pearson's correlation coefficients were utilized.

\section{Results}

\section{General}

While no quantitative analysis of facial dysmorphology was conducted, it was observed that no severe craniofacial abnormalities were present in adult mice. Some of the more extreme malformations caused by GD7 PAE previously discovered in GD17 fetuses, such as hydrocephaly and severe micrognathia, were not found in the current mice that survived to adulthood.

\section{Hypothalamic-Pituitary-Adrenal Axis Function}

Acute Restraint Stress-To evaluate HPA axis function, CORT and ACTH levels were measured after $5 \mathrm{~min}$ and $15 \mathrm{~min}$ of restraint stress (Fig. 1). Two-way ANOVA results demonstrated a significant main effect of time regardless of sex or hormone being analyzed (all $p$ 's $<0.0001$ ); CORT and ACTH levels were highest following the 15-min restraint stress. The CORT analysis revealed no significant prenatal treatment $\times$ time interaction for either males or females. However, there was a significant main effect of prenatal treatment for males $[F(1,53)=4.93, p<0.05]$, but not females (Fig. 1A, 1B). To indicate which groups were statistically different from each other based on post hoc analysis, letters were placed above each bar in the respective graphs, with like letters denoting statistical similarity and different letters representing statistical difference. Post hoc analysis revealed no prenatal treatment differences in CORT levels following 5 min of restraint stress for either males or females. However, when restraint stress was increased to $15 \mathrm{~min}$, male GD7 Alc mice showed increased CORT levels relative to male GD7 Con mice (c vs. d; $p<0.05$ ) (Fig. 1A). ACTH analysis revealed a significant prenatal treatment $\times$ time interaction for females $[F(2,52)=9.69, p<0.001]$, but not males (Fig. 1C, 1D). Post hoc analysis revealed that at 
15 min, female GD7 Alc mice showed increased ACTH levels relative to female GD7 Con mice (c vs. d, $p<0.001$ ) (Fig. 1D). Neither males nor females demonstrated a significant main effect of prenatal treatment. Results also showed that male and female GD7 Alc mice have a slightly dampened ACTH response to $5 \mathrm{~min}$ of restraint stress as indicated by their 5min restraint ACTH levels being similar to their baseline levels, but not statistically different from the ACTH levels of GD7 Con mice after 5 min of restraint (Fig. 1C, 1D).

To further evaluate HPA axis function, CORT and ACTH levels were measured 60 and 90 min after the end of restraint to reveal whether hormone levels differed over time (Fig. 2). Two-way ANOVA results demonstrated a significant main effect of time regardless of sex or hormone being analyzed (all $p$ 's $<0.0001$ ); CORT and ACTH levels were highest immediately after the stress and declined over time. The CORT analysis revealed no significant prenatal treatment $\times$ time interaction for either males or females. However, there was a significant main effect of prenatal treatment for males $[F(1,53)=7.13, p<0.01]$ (Fig. 2A). Post hoc analysis revealed that male GD7 Alc mice had significantly elevated CORT relative to GD7 Con mice at the 0 time point $(p<0.05)$. The CORT analysis for females demonstrated a trend toward a main effect of prenatal treatment $[F(1,56)=3.56, p=0.06]$ (Fig. 2B). ACTH analysis revealed a significant prenatal treatment $\times$ time interaction for females $[F(3,57)=5.39, p<0.01]$, but not males (Fig. 2C, 2D). Females, but not males, showed a significant main effect of prenatal treatment $[F(1,57)=6.67, p=0.01]$ (Fig. 2D).

Post hoc analysis demonstrated that female GD7 Alc mice had significantly elevated ACTH relative to GD7 Con mice at the 0 time point $(p<0.001)$.

Acute alcohol injection-HPA axis activity was also examined after exposure to an acute alcohol injection (Fig. 3). CORT and ACTH levels were measured at baseline and 20, 60 , or $120 \mathrm{~min}$ after a $2.0 \mathrm{~g} / \mathrm{kg}$ alcohol injection. Two-way ANOVA results again revealed a significant main effect of time regardless of sex or hormone being analyzed ( $p$ 's $<0.0001$ ), except there was only a trend for a difference across time when looking at ACTH levels measured in males $(p=0.08)$; hormone levels were highest 20 min after the alcohol injection and declined over time. The CORT analysis revealed no significant prenatal treatment $\times$ time interaction for either males or females. Males, but not females, showed an overall significant main effect of prenatal treatment $[F(1,63)=4.93, p<0.05]$ (Fig. 3A, 3B). The ACTH analysis revealed no significant prenatal treatment $\times$ time interaction for either males or females. Unlike the CORT results, females, but not males, showed a significant main effect of prenatal treatment $[F(1,65)=4.97, p<0.05]$ (Fig. 3C, 3D) on ACTH levels. Post hoc analysis demonstrated that female GD7 Alc mice had significantly blunted ACTH levels compared to GD7 Con mice at 60 min after acute alcohol injection $(p<0.05)$ (Fig. 3D).

Additional analysis revealed an interesting relationship between the time-course of BACs and CORT or ACTH levels. BACs were measured at the same time points after the acute alcohol injection as CORT and ACTH (Fig. 3E, 3F). Two-way ANOVA results revealed no significant prenatal treatment $\times$ time interaction, but there was a significant main effect of time ( $p<0.0001$ ); BACs were highest $20 \mathrm{~min}$ after injection and declined over time. When correlating BACs and CORT over time, regression analysis revealed an influence of sex (Supplemental Fig. 1). Over time, BACs and CORT levels were positively correlated in 
male mice, but not correlated in female mice. More noteworthy, regression analysis revealed a significant influence of prenatal treatment and sex on the correlation over time between BACs and ACTH levels (Fig. 4). Both male GD7 Con (Fig. 4A) and female GD7 Alc (Fig. 4D) mice displayed a significant positive correlation between BACs and ACTH levels, while male GD7 Alc (Fig. 4C) and female GD7 Con (Fig. 4B) mice displayed no significant correlation.

\section{Behavioral Measures}

Light-dark testing-Overall, male GD7 Alc mice displayed increased anxiety-like behavior, while female GD7 Alc mice displayed decreased anxiety-like behavior during light-dark testing (Fig. 5A-F). Two-way repeated-measures ANOVA revealed a significant main effect of time regardless of sex or behavioral measure being analyzed ( $p$ 's $<0.05$ ), except there was only a trend for a difference across time when looking at light duration in males $(p=0.08)$; light exploration fluctuated over time. There was no significant prenatal treatment $\times$ time interaction for any behavioral measures. However, there was a significant main effect of prenatal treatment on light duration $[F(1,15)=5.33, p<0.05]$ (Fig. 5C) and light distance $[F(1,15)=5.82, p<0.05]$ (Fig. 5E) in male mice. With both measures, male GD7 Alc mice displayed an overall decrease in light exploration relative to male GD7 Con mice. Conversely, female GD7 Alc mice displayed an overall increase in light exploration relative to female GD7 Con mice, as indicated by a significant main effect of prenatal treatment on light entries $[F(1,19)=4.23, p=0.05]$ (Fig. 5B).

Elevated Plus Maze $-t$ test analysis revealed a significant increase in percent time spent in the open arms for female GD7 Alc mice compared to female GD7 Con mice $(p<0.05)$ (Fig. 5H). No significant differences were seen in open-arm entries for females. Males showed no significant differences on either measure.

Forced swim test-Two-way repeated-measures ANOVA revealed no significant prenatal $\times$ time interaction, but there was a significant main effect of time for both males and females (all $p$ 's < 0.0001) (Fig. 6); immobility peaked at 4 min for males and increased over time for females. There was a trend toward a significant main effect of prenatal treatment in males $[F(1,19)=3.56, p=0.07]$. Post hoc analysis revealed a significant decrease in immobility duration at minute 4 for male GD7 Alc mice compared to male GD7 Con mice $(p<0.05)$ (Fig. 6A). Female mice showed no significant main effect of prenatal treatment on immobility duration (Fig. 6B). Total distance traveled was the same between prenatal treatment groups for both males and females (data not shown).

\section{Discussion}

The results of this study demonstrate that a single, binge-like exposure to alcohol early in gestation is sufficient to cause persistent HPA axis and behavioral abnormalities in the offspring. Specifically, HPA axis activity is affected differentially depending on the type of stimulus (i.e., acute stress or acute alcohol injection). Moreover, measures of anxiety- and depression-like behavior reveal a sexually dimorphic response. As discussed below, these 
results support an influence of PAE on stress reactivity and extend previous findings to identify a critical developmental period of vulnerability during early gestation.

The current study reveals that both male and female GD7 Alc mice displayed increased HPA axis activity following acute restraint stress exposure. Multiple other animal studies using a range of PAE paradigms show findings consistent with the current results following stress exposure (Kim, Giberson, et al., 1999; Lee et al., 1990; Nelson et al., 1986; Schneider et al., 2002; Taylor et al., 1982; Weinberg, 1992). Interestingly, there was a sex difference in the endocrine marker that was most affected by PAE. Male GD7 Alc mice displayed a greater CORT response, while female GD7 Alc mice displayed a greater ACTH response. In the current study, HPA activity was measured in naturally cycling female mice. Previously, it has been shown in rats that gonadal hormones mediate the effects of alcohol on HPA axis activity. During proestrus, when estradiol and progesterone levels peak, prenatal alcoholexposed rats showed elevated CORT levels at baseline and after stress relative to control rats, while ACTH levels were less regulated by estrous cycle but still increased overall (Lan et al., 2009). Therefore, CORT levels, which appear less affected in the current study by GD7 PAE in female mice, may be more influenced by estrous cycle. The lack of significant change between female GD7 Con and GD7 Alc mice may be a result of collapsing data across all stages of the estrous cycle. However, the small within-group variation (as reflected by the low SEM) suggests that the current cohort of mice was not significantly influenced by estrous cycle. Overall, though, these results suggest that early PAE is indeed sufficient to alter HPA axis activity in response to an acute stressor. Moreover, since the increased HPA axis responsiveness differed between males and females, this work also highlights the need to examine multiple endocrine factors.

Further analysis of HPA axis reactivity after an acute alcohol injection also revealed a sexually dimorphic response. Male GD7 Alc mice displayed an overall increase in CORT and an observable, but not significant, lack of increase in ACTH at $20 \mathrm{~min}$, the time of peak ACTH levels in the GD7 Con mice. The increase in CORT may be a reflection of increased responsiveness to the stress of an injection by male GD7 Alc mice. More interestingly, though, female GD7 Alc mice showed no differences in the CORT response, but a significant blunting of ACTH levels. The stress of an injection may be different between GD7 Con and GD7 Alc mice (as acknowledged with the CORT response), but data not reported here showed no differences in ACTH levels after a saline injection. Thus, the overall blunted ACTH levels in GD7 Alc mice likely reflects an acute alcohol-specific effect. Interestingly, clinical research illustrates blunted ACTH and cortisol responses following an acute alcohol injection among individuals at risk for developing alcohol-abuse disorders (Schuckit, Risch, \& Gold, 1988; Schuckit, Tsuang, Anthenilli, Tipp, \& Nurnberger, 1996). A significant study examining adverse life outcomes in individuals with FAS or fetal alcohol effects showed a $46 \%$ prevalence of alcohol and drug problems in adults age 21 and older (Streissguth et al., 2004). Thus, the increased prevalence of alcohol abuse in adults with PAE may be associated with alterations in HPA reactivity to alcohol; this possibility warrants further investigation.

Correlative analysis revealed an interesting relationship between the time course of ACTH and CORT levels and BACs. The correlation between ACTH, but not CORT, levels and 
BACs was influenced by prenatal treatment. This suggests that PAE on GD7 may more significantly affect development of the pituitary compared to the adrenal gland, and the HPA alterations present in the current study may be reflective of these changes. More specifically, ACTH levels are positively correlated with BACs in male GD7 Con and female GD7 Alc mice but not their respective counterparts, further suggesting that sex and prenatal treatment interact to influence ACTH levels. Several studies show that PAE (as well as other prenatal stressors) can contribute to the feminization of male rodents and masculinization of female rodents (Halasz, Aird, Prystowsky, \& Redei, 1993; McGivern, Clancy, Hill, \& Noble, 1984; Meyer \& Riley, 1986; Udani, Parker, Gavaler, \& Van Thiel, 1985; Ward, Ward, Winn, \& Bielawski, 1994). Thus, the current HPA axis results support these findings, suggesting that early PAE can cause sexually dimorphic HPA axis responses.

The current study also highlights neurobehavioral phenotypic variation that is qualitatively different between males and females. Both a light-dark chamber and elevated plus maze were used to test anxiety-like behavior; these procedures are sensitive to changes in anxietylike behavior because anxiolytic drugs influence specific behavioral measures (Crawley \& Goodwin, 1980; Pellow, Chopin, File, \& Briley, 1985). Male GD7 Alc mice displayed increased anxiety-like behavior as measured by decreased light duration and distance during light-dark testing. Conversely, female GD7 Alc mice displayed reduced anxiety-like behavior as measured by increased light entries during light-dark testing. This effect in females was also supported by increased time spent in the open arms on the elevated plus maze. The increased anxiety-like behavior in male GD7 Alc mice corroborates previous studies focusing on more moderate alcohol exposure throughout gestation (Carneiro et al., 2005; Dursun et al., 2006; Hellemans et al., 2008; Liang et al., 2014); however, the decrease in anxiety-like behavior in female GD7 Alc mice is novel compared to these previous findings. Subsequent analysis of the light-dark and elevated plus maze tests revealed that female mice showed a significant positive correlation between all behavioral measurements analyzed during both tests; that is, as light exploration during light-dark testing increased, so did open-arm exploration during the elevated plus maze. Thus, individual differences in anxiety-like behavior were cross-validated between behavioral measurements, suggesting consistency and appropriateness of using these tests to analyze anxiety-like behavior.

Qualitative sex differences in response to PAE were further seen when using the forced swim test to assess depression-like behavior. Male GD7 Alc mice showed decreased immobility on the forced swim test, reflective of decreased depression-like behavior, while females showed no differences. There were no differences in total distance traveled during the forced swim test, which suggests that differences in immobility are likely not modulated by motor differences. The females' behavior is in contrast to previous findings, which show no depression (Sanchez Vega, Chong, \& Burne, 2013) or increased depression-like (Carneiro et al., 2005; Hellemans, Verma, et al., 2010; Wilcoxon et al., 2005) behavior following PAE. The differing results among these studies are likely reflective of differences in the amount and pattern of alcohol exposure as the above studies focused on low to moderate chronic alcohol exposure. The forced swim results for the males corroborate one previous study examining depressive-like behavior in prenatal alcohol-exposed rats following chronic mild stress (Hellemans, Verma, et al., 2010). Immobility is often interpreted as "behavioral despair", because of the ability of antidepressants to reverse 
immobility on this test (Petit-Demouliere, Chenu, \& Bourin, 2005). However, some literature suggests that immobility is actually reflective of a successful coping strategy employed to conserve energy (Borsini \& Meli, 1988; Nishimura, Tsuda, Oguchi, Ida, \& Tanaka, 1988; West, 1990). Thus, the results would then suggest that male GD7 Alc mice might have cognitive deficits that do not allow them to recognize the situation as detrimental, but future studies would need to be conducted to be able to better interpret these results.

While the alterations in HPA axis function and behavior found in this study are likely directly influenced by alcohol's effect on the development of the pituitary and/or hypothalamus, it is important to note that GD7 PAE has been shown to also cause forebrain deficiencies that extend beyond these regions (Godin et al., 2010; Lipinski et al., 2012; Sulik, Johnston, \& Webb, 1981; Sulik, Lauder, \& Dehart, 1984). For example, the hippocampus and septal region are affected after GD7 PAE, and both areas regulate emotion. This may partly be due to their ability to influence the HPA axis. Thus, the brain regions involved in the GD7 alcohol-induced behavioral changes may not be exclusively and directly modulated by direct HPA axis.

GD7 PAE in mice not only results in brain dysmorphology, but can also cause clear facial dysmorphology. Face-brain dysmorphology patterns are positively correlated (Godin et al., 2010; Lipinski et al., 2012). Prior studies using this PAE paradigm focused on consequences at the fetal stage, with the current study being the first to focus on more long-term consequences in adult mice. The present study finds that most GD7 Alc mice that survive into adulthood do not show obvious facial dysmorphology; yet, they show small but consistent HPA and behavioral abnormalities. Although litter sizes did not differ significantly between control and alcohol-treated mice, it could be suggested that some of the more severely affected alcohol-treated mice did not survive, and thus, explains why the results may not be larger in magnitude. These animal findings provide critical support for the new diagnosis, ND-PAE, which came out in DSM-5 and supports the prevalence of mental disturbances after PAE in the absence of any physical deficits.

Collectively, this work contributes significantly to defining the functional abnormalities that can occur after prenatal alcohol insult early in gestation. Males and females were differentially affected after early PAE, therefore highlighting the importance of analyzing both sexes during studies. The two stimulus challenges revealed that early PAE leads to overall HPA axis dysfunction but the response can differ depending on the type of stimulus. Further studies need to be conducted in order to understand the mechanisms driving these responses. The results discussed here are especially important in light of the report revealing that half of all pregnant women in the U.S. drank alcohol during the 3 months preceding pregnancy recognition and the majority did not know they were pregnant until after the fourth week of pregnancy (Floyd, Decouflé, \& Hungerford, 1999). These findings are of clinical importance because they emphasize the significance of avoiding alcohol during even the early stages of pregnancy. Awareness of the full range of potential consequences following PAE is also expected to improve diagnosis and treatment. 


\section{Supplementary Material}

Refer to Web version on PubMed Central for supplementary material.

\section{Acknowledgments}

All or part of this work was done in conjunction with the Collaborative Initiative on Fetal Alcohol Spectrum Disorders (CIFASD), which is funded by grants from the National Institute on Alcohol Abuse and Alcoholism (NIAAAA). Additional information about CIFASD can be found at www.cifasd.org. This work was supported by NIAAA grants AA007573, AA021651, AA011605. All behavior data was gathered from the Mouse Behavioral Phenotyping Core at the University of North Carolina, Chapel Hill under the guidance of Dr. Sheryl Moy and supported by the National Institute of Child Health and Human Development grant U54HD079124, PI: Dr. Joseph Piven.

\section{References}

Appelhof BC, Huyser J, Verweij M, Brouwer JP, van Dyck R, Fliers E, et al. Glucocorticoids and relapse of major depression (dexamethasone/corticotropin-releasing hormone test in relation to relapse of major depression). Biological Psychiatry. 2006; 59:696-701. [PubMed: 16368077]

Barr HM, Bookstein FL, O’Malley KD, Connor PD, Huggins JE, Streissguth AP. Binge drinking during pregnancy as a predictor of psychiatric disorders on the Structured Clinical Interview for DSM-IV in young adult offspring. The American Journal of Psychiatry. 2006; 163:1061-1065. [PubMed: 16741207]

Borsini F, Meli A. Is the forced swimming test a suitable model for revealing antidepressant activity? Psychopharmacology (Berl). 1988; 94:147-160. [PubMed: 3127840]

Burke HM, Davis MC, Otte C, Mohr DC. Depression and cortisol responses to psychological stress: a meta-analysis. Psychoneuroendocrinology. 2005; 30:846-856. [PubMed: 15961250]

Carneiro LM, Diógenes JP, Vasconcelos SM, Aragão GF, Noronha EC, Gomes PB, et al. Behavioral and neurochemical effects on rat offspring after prenatal exposure to ethanol. Neurotoxicology and Teratology. 2005; 27:585-592. [PubMed: 16039829]

Coulter CL, Leech RW, Schaefer GB, Scheithauer BW, Brumback RA. Midline cerebral dysgenesis, dysfunction of the hypothalamic-pituitary axis, and fetal alcohol effects. Archives of Neurology. 1993; 50:771-775. [PubMed: 8323485]

Crawley J, Goodwin FK. Preliminary report of a simple animal behavior model for the anxiolytic effects of benzodiazepines. Pharmacology, Biochemistry, and Behavior. 1980; 13:167-170.

Cryan JF, Markou A, Lucki I. Assessing antidepressant activity in rodents: recent developments and future needs. Trends in Pharmacological Sciences. 2002; 23:238-245. [PubMed: 12008002]

De Bellis MD. Developmental traumatology: a contributory mechanism for alcohol and substance use disorders. Psychoneuroendocrinology. 2002; 27:155-170. [PubMed: 11750776]

Dursun I, Jakubowska-Doğru E, Uzbay T. Effects of prenatal exposure to alcohol on activity, anxiety, motor coordination, and memory in young adult Wistar rats. Pharmacology, Biochemistry, and Behavior. 2006; 85:345-355.

Famy C, Streissguth AP, Unis AS. Mental illness in adults with fetal alcohol syndrome or fetal alcohol effects. The American Journal of Psychiatry. 1998; 155:552-554. [PubMed: 9546004]

Floyd RL, Decouflé P, Hungerford DW. Alcohol use prior to pregnancy recognition. American Journal of Preventive Medicine. 1999; 17:101-107. [PubMed: 10490051]

Fryer SL, McGee CL, Matt GE, Riley EP, Mattson SN. Evaluation of psychopathological conditions in children with heavy prenatal alcohol exposure. Pediatrics. 2007; 119:e733-741. [PubMed: 17332190]

Godin EA, O'Leary-Moore SK, Khan AA, Parnell SE, Ament JJ, Dehart DB, et al. Magnetic resonance microscopy defines ethanol-induced brain abnormalities in prenatal mice: effects of acute insult on gestational day 7. Alcoholism: Clinical and Experimental Research. 2010; 34:98111.

Gordon HW. Early environmental stress and biological vulnerability to drug abuse. Psychoneuroendocrinology. 2002; 27:115-126. [PubMed: 11750773] 
Halasz I, Aird F, Li L, Prystowsky MB, Redei E. Sexually dimorphic effects of alcohol exposure in utero on neuroendocrine and immune functions in chronic alcohol-exposed adult rats. Molecular and Cellular Neuroscience. 1993; 4:343-353. [PubMed: 19912941]

Haley DW, Handmaker NS, Lowe J. Infant stress reactivity and prenatal alcohol exposure. Alcoholism: Clinical and Experimental Research. 2006; 30:2055-2064.

Hellemans KG, Sliwowska JH, Verma P, Weinberg J. Prenatal alcohol exposure: fetal programming and later life vulnerability to stress, depression and anxiety disorders. Neuroscience and Biobehavioral Reviews. 2010; 34:791-807. [PubMed: 19545588]

Hellemans KG, Verma P, Yoon E, Yu W, Weinberg J. Prenatal alcohol exposure increases vulnerability to stress and anxiety-like disorders in adulthood. Annals of the New York Academy of Sciences. 2008; 1144:154-175. [PubMed: 19076375]

Hellemans KG, Verma P, Yoon E, Yu WK, Young AH, Weinberg J. Prenatal alcohol exposure and chronic mild stress differentially alter depressive- and anxiety-like behaviors in male and female offspring. Alcoholism: Clinical and Experimental Research. 2010; 34:633-645.

Jacobson SW, Bihun JT, Chiodo LM. Effects of prenatal alcohol and cocaine exposure on infant cortisol levels. Development and Psychopathology. 1999; 11:195-208. [PubMed: 16506530]

Kim CK, Giberson PK, Yu W, Zoeller RT, Weinberg J. Effects of prenatal ethanol exposure on hypothalamic-pituitary-adrenal responses to chronic cold stress in rats. Alcoholism: Clinical and Experimental Research. 1999; 23:301-310.

Kim CK, Turnbull AV, Lee SY, Rivier CL. Effects of prenatal exposure to alcohol on the release of adenocorticotropic hormone, corticosterone, and proinflammatory cytokines. Alcoholism: Clinical and Experimental Research. 1999; 23:52-59.

Kotch LE, Sulik KK. Patterns of ethanol-induced cell death in the developing nervous system of mice; neural fold states through the time of anterior neural tube closure. International Journal of Developmental Neuroscience. 1992; 10:273-279. [PubMed: 1414440]

Lan N, Yamashita F, Halpert AG, Sliwowska JH, Viau V, Weinberg J. Effects of prenatal ethanol exposure on hypothalamic-pituitary-adrenal function across the estrous cycle. Alcoholism: Clinical and Experimental Research. 2009; 33:1075-1088.

Lee S, Imaki T, Vale W, Rivier C. Effect of prenatal exposure to ethanol on the activity of the hypothalamic-pituitary-adrenal axis of the offspring: Importance of the time of exposure to ethanol and possible modulating mechanisms. Molecular and Cellular Neurosciences. 1990; 1:168-177. [PubMed: 19912768]

Liang J, Shen Y, Shao XM, Scott MB, Ly E, Wong S, et al. Dihydromyricetin prevents fetal alcohol exposure-induced behavioral and physiological deficits: the roles of GABAA receptors in adolescence. Neurochemical Research. 2014; 39:1147-1161. [PubMed: 24676702]

Lipinski RJ, Hammond P, O'Leary-Moore SK, Ament JJ, Pecevich SJ, Jiang Y, et al. Ethanol-induced face-brain dysmorphology patterns are correlative and exposure-stage dependent. PLoS One. 2012; 7:e43067. [PubMed: 22937012]

Macrì S, Spinelli S, Adriani W, Dee Higley J, Laviola G. Early adversity and alcohol availability persistently modify serotonin and hypothalamic-pituitary-adrenal-axis metabolism and related behavior: what experimental research on rodents and primates can tell us. Neuroscience and Biobehavioral Reviews. 2007; 31:172-180. [PubMed: 16956661]

May PA, Gossage JP, Kalberg WO, Robinson LK, Buckley D, Manning M, et al. Prevalence and epidemiologic characteristics of FASD from various research methods with an emphasis on recent in-school studies. Developmental Disabilities Research Reviews. 2009; 15:176-192. [PubMed: 19731384]

McGivern RF, Clancy AN, Hill MA, Noble EP. Prenatal alcohol exposure alters adult expression of sexually dimorphic behavior in the rat. Science. 1984; 224:896-898. [PubMed: 6719121]

Meyer LS, Riley EP. Social play in juvenile rats prenatally exposed to alcohol. Teratology. 1986; 34:1-7. [PubMed: 3764769]

Nelson LR, Taylor AN, Lewis JW, Poland RE, Redei E, Branch BJ. Pituitary-adrenal responses to morphine and footshock stress are enhanced following prenatal alcohol exposure. Alcoholism: Clinical and Experimental Research. 1986; 10:397-402. 
Nemeroff CB, Widerlöv E, Bissette G, Walléus H, Karlsson I, Eklund K, et al. Elevated concentrations of CSF corticotropin-releasing factor-like immunoreactivity in depressed patients. Science. 1984; 226:1342-1344. [PubMed: 6334362]

Nishimura H, Tsuda A, Oguchi M, Ida Y, Tanaka M. Is immobility of rats in the forced swim test “behavioral despair"? Physiology \& Behavior. 1988; 42:93-95. [PubMed: 3387484]

O'Connor MJ, Kasari C. Prenatal alcohol exposure and depressive features in children. Alcoholism: Clinical and Experimental Research. 2000; 24:1084-1092.

O'Connor MJ, Shah B, Whaley S, Cronin P, Gunderson B, Graham J. Psychiatric illness in a clinical sample of children with prenatal alcohol exposure. The American Journal of Drug and Alcohol Abuse. 2002; 28:743-754. [PubMed: 12492268]

Ogilvie KM, Rivier C. Prenatal alcohol exposure results in hyperactivity of the hypothalamic-pituitaryadrenal axis of the offspring: modulation by fostering at birth and postnatal handling. Alcoholism: Clinical and Experimental Research. 1997; 21:424-429.

Osborn JA, Kim CK, Steiger J, Weinberg J. Prenatal ethanol exposure differentially alters behavior in males and females on the elevated plus maze. Alcoholism: Clinical and Experimental Research. 1998; 22:685-696.

Peiffer J, Majewski F, Fischbach H, Bierich JR, Volk B. Alcohol embryo- and fetopathy. Neuropathology of 3 children and 3 fetuses. Journal of the Neurological Sciences. 1979; 41:125137. [PubMed: 438847]

Pellow S, Chopin P, File SE, Briley M. Validation of open:closed arm entries in an elevated plus-maze as a measure of anxiety in the rat. Journal of Neuroscience Methods. 1985; 14:149-167. [PubMed: 2864480]

Petit-Demouliere B, Chenu F, Bourin M. Forced swimming test in mice: a review of antidepressant activity. Psychopharmacology (Berl). 2005; 177:245-255. [PubMed: 15609067]

Rasmussen C, Andrew G, Zwaigenbaum L, Tough S. Neurobehavioural outcomes of children with fetal alcohol spectrum disorders: A Canadian perspective. Paediatrics \& Child Health. 2008; 13:185-191. [PubMed: 19252695]

Riley EP, Infante MA, Warren KR. Fetal alcohol spectrum disorders: an overview. Neuropsychology Review. 2011; 21:73-80. [PubMed: 21499711]

Sanchez Vega MC, Chong S, Burne TH. Early gestational exposure to moderate concentrations of ethanol alters adult behaviour in C57BL/6J mice. Behavioural Brain Research. 2013; 252:326333. [PubMed: 23756143]

Schneider ML, Moore CF, Kraemer GW, Roberts AD, DeJesus OT. The impact of prenatal stress, fetal alcohol exposure, or both on development: perspectives from a primate model. Psychoneuroendocrinology. 2002; 27:285-298. [PubMed: 11750784]

Schuckit MA, Risch SC, Gold EO. Alcohol consumption, ACTH level, and family history of alcoholism. The American Journal of Psychiatry. 1988; 145:1391-1395. [PubMed: 2847567]

Schuckit MA, Tsuang JW, Anthenelli RM, Tipp JE, Nurnberger JI Jr. Alcohol challenges in young men from alcoholic pedigrees and control families: a report from the COGA project. Journal of Studies on Alcohol. 1996; 57:368-377. [PubMed: 8776678]

Schüle C, Baghai TC, Eser D, Rupprecht R. Hypothalamic-pituitary-adrenocortical system dysregulation and new treatment strategies in depression. Expert Review of Neurotherapeutics. 2009; 9:1005-1019. [PubMed: 19589050]

Somers JM, Goldner EM, Waraich P, Hsu L. Prevalence and incidence studies of anxiety disorders: a systematic review of the literature. Canadian Journal of Psychiatry. 2006; 51:100-113.

Steinhausen HC, Willms J, Metzke CW, Spohr HL. Behavioural phenotype in foetal alcohol syndrome and foetal alcohol effects. Developmental Medicine and Child Neurology. 2003; 45:179-182. [PubMed: 12613774]

Streissguth, AP.; Barr, HM.; Kogan, J.; Bookstein, FL. Final Report to the Centers for Disease Control and Prevention (CDC). Seattle: University of Washington, Fetal Alcohol \& Drug Unit; 1996 Aug. Understanding the occurrence of secondary disabilities in clients with Fetal Alcohol Syndrome (FAS) and Fetal Alcohol Effects (FAE). Tech. Rep. No. 96-06 
Streissguth AP, Bookstein FL, Barr HM, Sampson PD, O’Malley K, Young JK. Risk factors for adverse life outcomes in fetal alcohol syndrome and fetal alcohol effects. Journal of Developmental and Behavioral Pediatrics. 2004; 25:228-238. [PubMed: 15308923]

Sulik KK, Johnston MC, Webb MA. Fetal alcohol syndrome: embryogenesis in a mouse model. Science. 1981; 214:936-938. [PubMed: 6795717]

Sulik KK, Lauder JM, Dehart DB. Brain malformations in prenatal mice following acute maternal ethanol administration. International Journal of Developmental Neuroscience. 1984; 2:203-214. [PubMed: 24874034]

Taylor AN, Branch BJ, Liu SH, Kokka N. Long-term effects of fetal ethanol exposure on pituitaryadrenal response to stress. Pharmacology, Biochemistry, and Behavior. 1982; 16:585-589.

Udani M, Parker S, Gavaler J, Van Thiel DH. Effects of in utero exposure to alcohol upon male rats. Alcoholism: Clinical and Experimental Research. 1985; 9:355-359.

Vreeburg SA, Hoogendijk WJ, van Pelt J, Derijk RH, Verhagen JC, van Dyck R, et al. Major depressive disorder and hypothalamic-pituitary-adrenal axis activity: results from a large cohort study. Archives of General Psychiatry. 2009; 66:617-626. [PubMed: 19487626]

Ward IL, Ward OB, Winn RJ, Bielawski D. Male and female sexual behavior potential of male rats prenatally exposed to the influence of alcohol, stress, or both factors. Behavioral Neuroscience. 1994; 108:1188-1195. [PubMed: 7893411]

Weinberg J. Prenatal ethanol effects: sex differences in offspring stress responsiveness. Alcohol. 1992; 9:219-223. [PubMed: 1605890]

Weinberg J, Sliwowska JH, Lan N, Hellemans KG. Prenatal alcohol exposure: foetal programming, the hypothalamic-pituitary-adrenal axis and sex differences in outcome. Journal of Neuroendocrinology. 2008; 20:470-488. [PubMed: 18266938]

Weinberg J, Taylor AN, Gianoulakis C. Fetal ethanol exposure: hypothalamic-pituitary-adrenal and beta-endorphin responses to repeated stress. Alcoholism: Clinical and Experimental Research. 1996; 20:122-131.

West AP. Neurobehavioral studies of forced swimming: the role of learning and memory in the forced swim test. Progress in Neuro-psychopharmacology \& Biological Psychiatry. 1990; 14:863-877. [PubMed: 2277851]

Wilcoxon JS, Kuo AG, Disterhoft JF, Redei EE. Behavioral deficits associated with fetal alcohol exposure are reversed by prenatal thyroid hormone treatment: a role for maternal thyroid hormone deficiency in FAE. Molecular Psychiatry. 2005; 10:961-971. [PubMed: 15940294]

Wingenfeld K, Wolf OT. HPA axis alterations in mental disorders: impact on memory and its relevance for therapeutic interventions. CNS Neuroscience \& Therapeutics. 2011; 17:714-722. [PubMed: 21143429]

Young EA, Abelson JL, Cameron OG. Effect of comorbid anxiety disorders on the hypothalamicpituitary-adrenal axis response to a social stressor in major depression. Biological Psychiatry. 2004; 56:113-120. [PubMed: 15231443]

Zobel AW, Nickel T, Sonntag A, Uhr M, Holsboer F, Ising M. Cortisol response in the combined dexamethasone/CRH test as predictor of relapse in patients with remitted depression. a prospective study. Journal of Psychiatric Research. 2001; 35:83-94. [PubMed: 11377437] 


\section{HIGHLIGHTS}

- Mice were exposed to an early binge-like dose of alcohol on gestational day 7.

- HPA axis-associated changes were examined once the offspring reached adulthood.

- Early alcohol exposure causes HPA axis dysfunction following multiple stressors.

- Early alcohol exposure causes sexually dimorphic behavioral abnormalities.

- The results suggest that a binge-like exposure can cause long lasting consequences. 
A

C
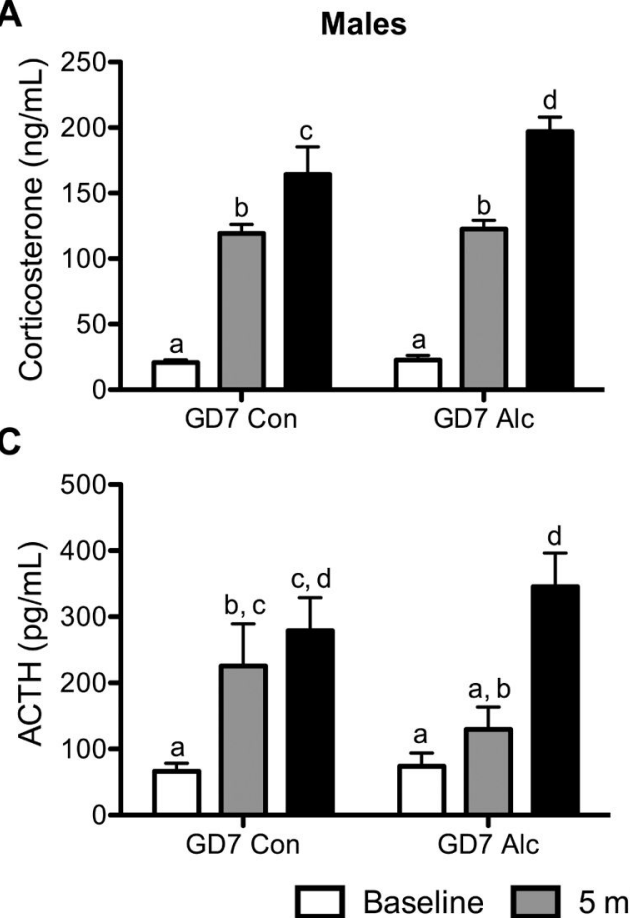

B

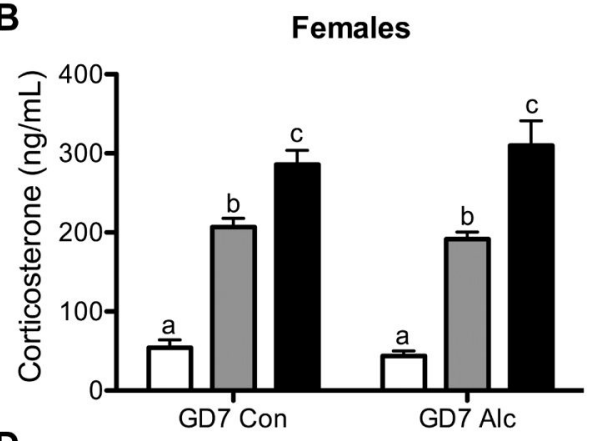

D

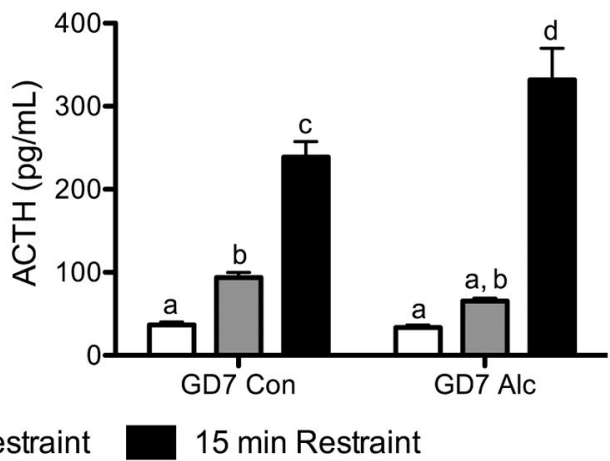

Figure 1. PAE increases HPA axis activity after acute restraint stress

CORT $(\mathbf{A}, \mathbf{B})$ and ACTH (C,D) were measured under basal conditions and after $5 \mathrm{~min}$ and 15 min of restraint stress in males (left column) and females (right column). Letters above each bar ( $a, b, c$, or d) denote the groups that are statistically similar, e.g., a bar with the letter ' $a$ ' above it is statistically similar to all other bars with an ' $a$ ' above them. All groups that are statistically different have $p$ 's $<0.05$. Male ( $n$ 's $)=$ baseline (13-17), $5 \mathrm{~min}(7-11)$, $15 \min (47)$; female ( $n$ 's) = baseline (12-17), $5 \min (7-9), 15 \min (5-7)$. 
A

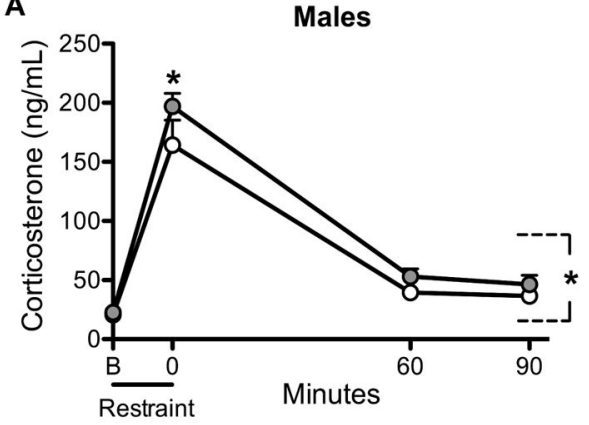

C

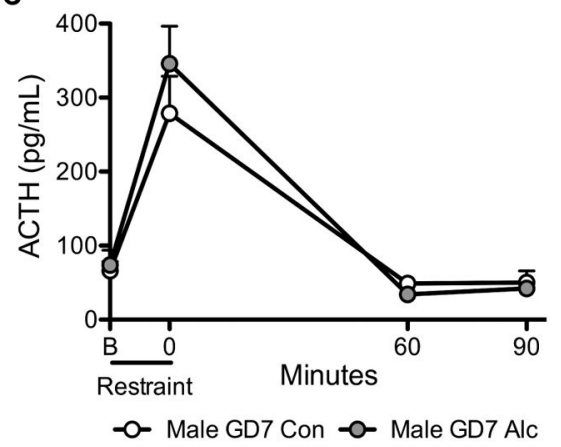

B

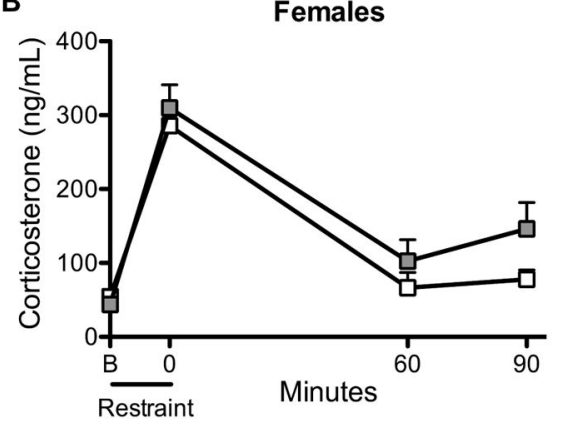

D

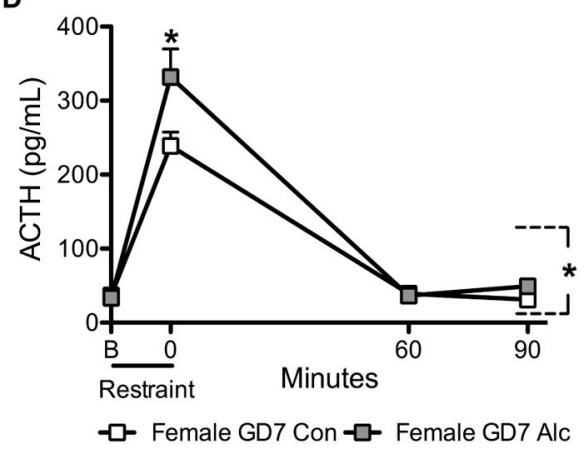

Figure 2. PAE increases HPA axis activity over time following acute restraint stress CORT (A,B) and ACTH (C,D) were measured 60 and 90 min following a 15-min restraint period in males (left column) and females (right column). The baseline and 15-min restraint time points shown in Fig. 1 were graphed in Fig. 2 as B and 0 min, respectively, in order to better depict the profile of CORT and ACTH levels over time. *with bracket $p<0.05$, significant main effect of prenatal treatment; * $p<0.05$, GD7 Alc vs. GD7 Con; Male ( $n$ 's) = baseline (13-17), $5 \mathrm{~min}$ (7-11), $15 \mathrm{~min}(4-7), 60 \mathrm{~min}(4-7), 90 \mathrm{~min}(3-6)$; female ( $n$ 's) = baseline (12-17), $5 \min (7-9), 15 \min (5-7), 60 \min (5-7), 90 \min (4-7)$. 
A

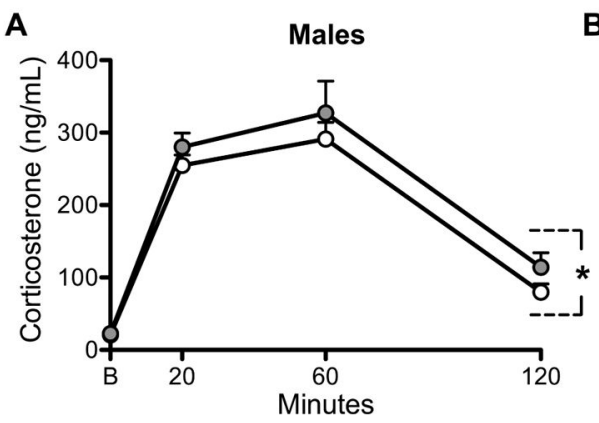

C
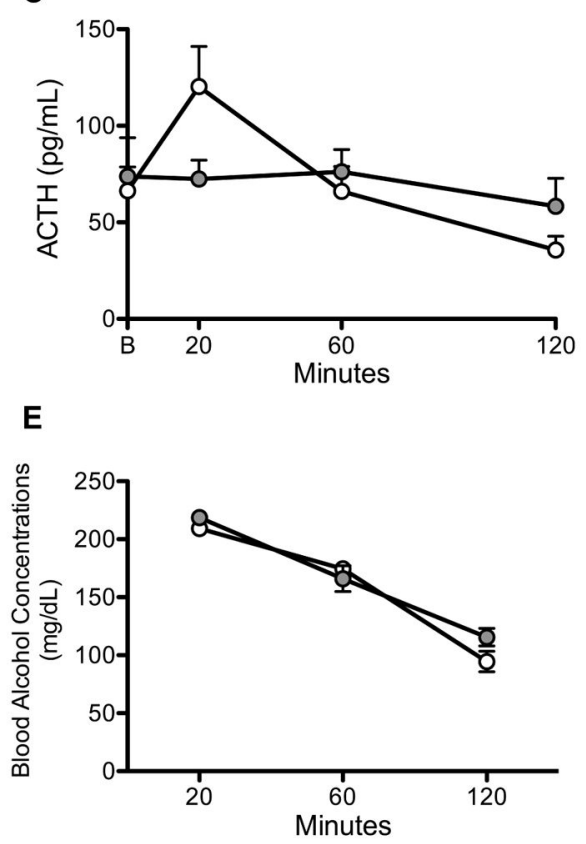

- - Male GD7 Con - - - Male GD7 Alc

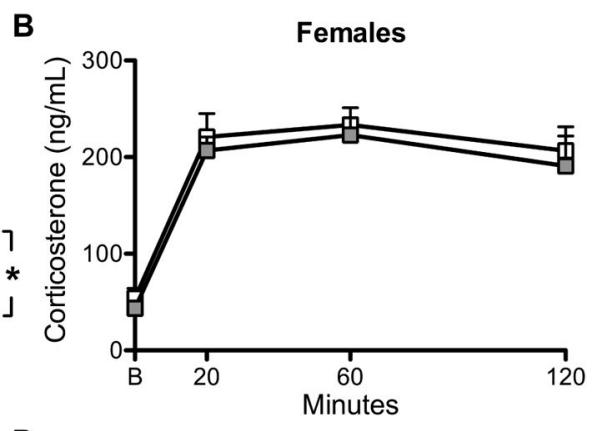

D

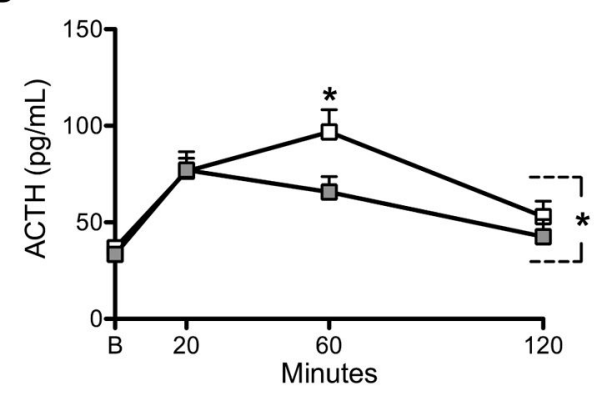

$\mathbf{F}$

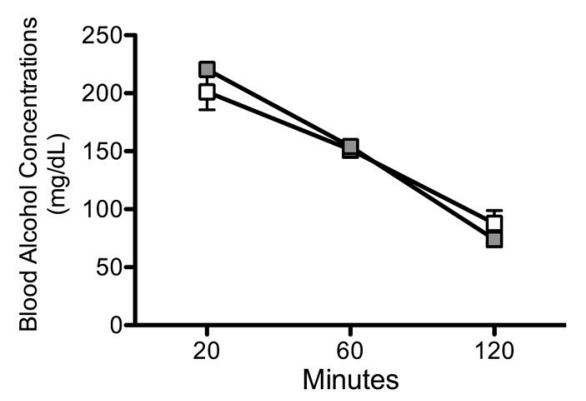

$\neg-$ Female GD7 Con - $\square-$ Female GD7 Alc

Figure 3. PAE causes HPA axis dysfunction after an acute alcohol injection

CORT (A,B) and ACTH (C,D) were measured under basal conditions and 20, 60, and 120 min after a $2.0 \mathrm{~g} / \mathrm{kg}$ alcohol injection in males (left column) and females (right column).

BACs $(\mathbf{E}, \mathbf{F})$ were measured at 20, 60, and $120 \mathrm{~min} .{ }^{*}$ with bracket $p<0.05$, significant main effect of prenatal treatment; Male ( $n$ 's) $=20 \mathrm{~min}(7-8), 60 \mathrm{~min}(4-6), 90 \mathrm{~min}(6-8)$; female $(n ' s)=20 \min (6-7), 60 \min (7-8), 90 \min (8)$. 
A

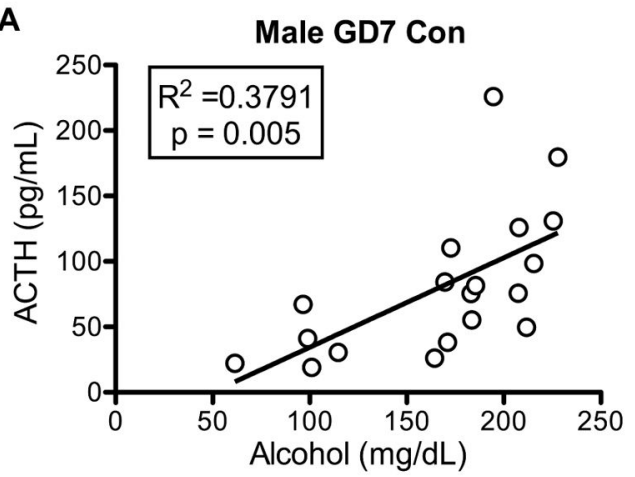

C

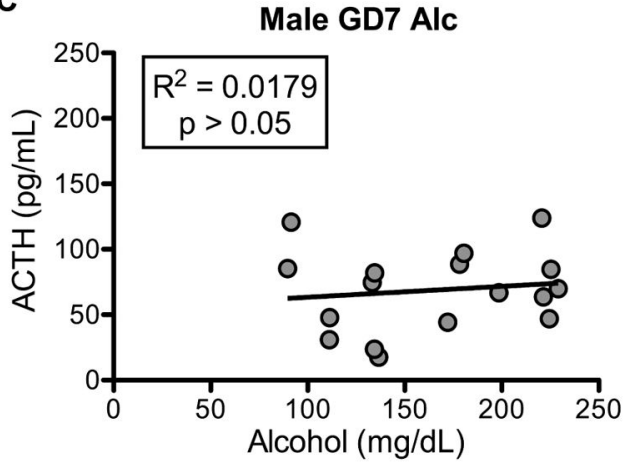

B

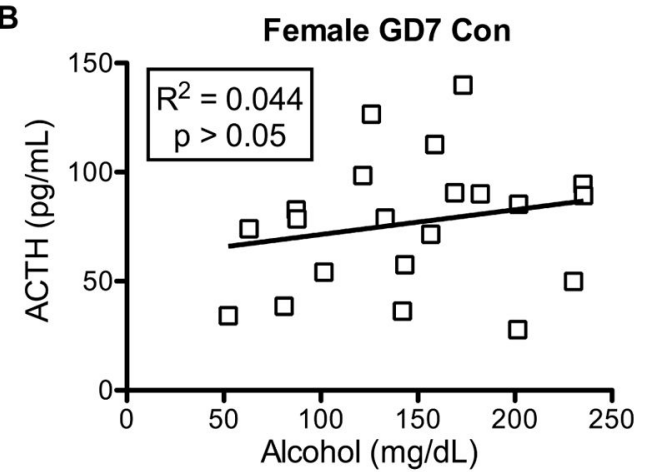

D

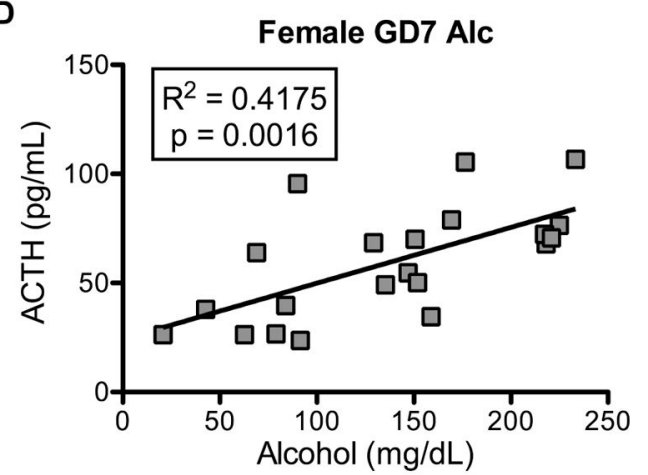

Figure 4. PAE and sex interact to influence the relationship between BACs and ACTH levels Regression analysis of BACs and ACTH levels in males (left column) and females (right column) exposed prenatally to vehicle (Ringer's solution) (A,B) or alcohol (C,D). BACs and ACTH levels positively correlate in male GD7 Con and female GD7 Alc mice but not male GD7 Alc and female GD7 Con mice. Male ( $n$ 's) = GD7 Con (19), GD7 Alc (17); female $(n$ 's) = GD7 Con (21), GD7 Alc (21). 

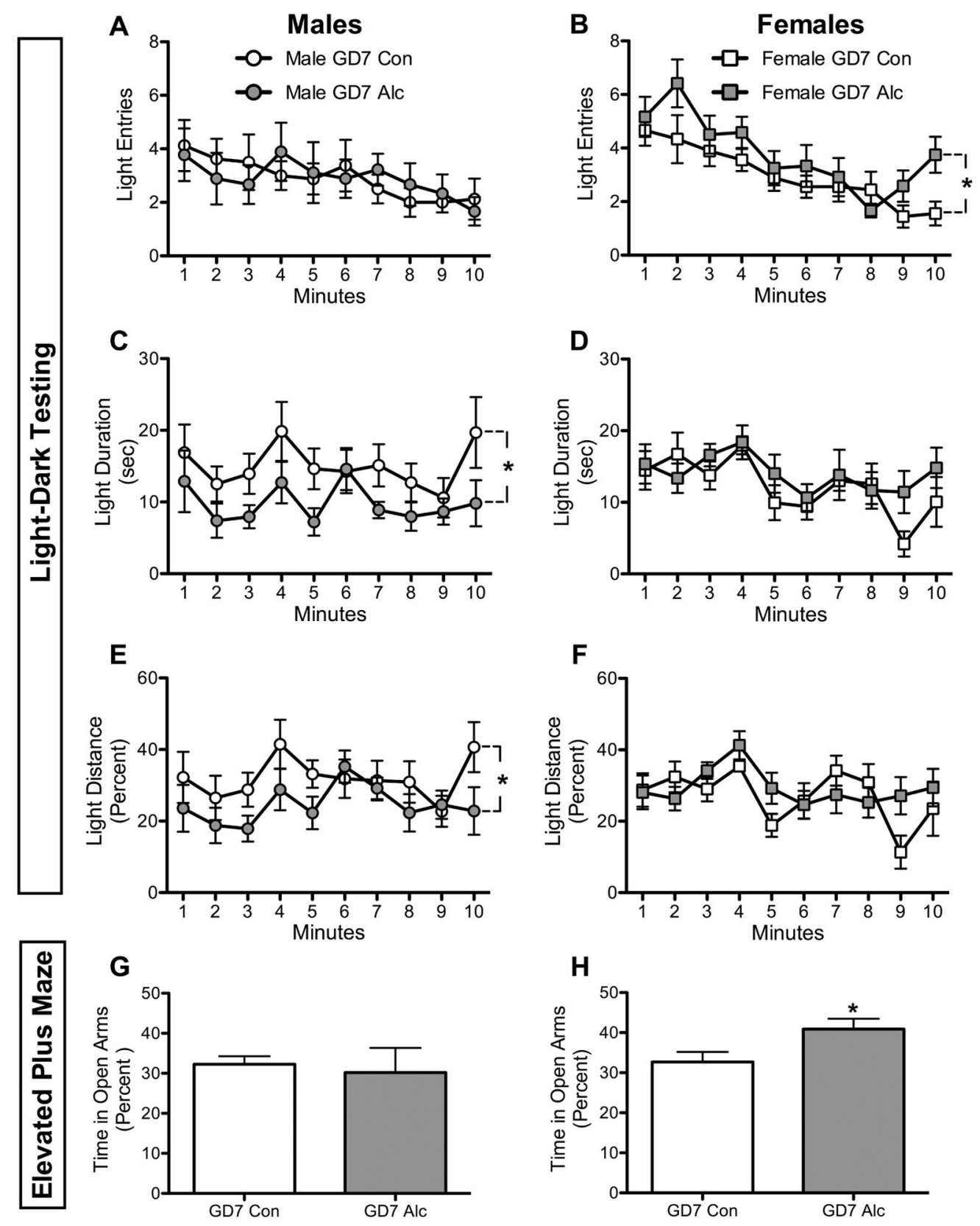

Figure 5. PAE affects anxiety-like behavior in a sexually dimorphic manner

Mice were tested on two procedures that measure anxiety-like behavior, light-dark testing (A-F) and elevated plus maze (G-H). Light entries (A,B), light duration $(\mathbf{C}, \mathbf{D})$ and percent light distance ([light distance/(light + dark distance) $] \times 100)(\mathbf{E}, \mathbf{F})$ were measured during light-dark testing, while percent time spent in the open arms ([open arms time/(closed + open arms time) $] \times 100)(\mathbf{G}, \mathbf{H})$ was measured on the elevated plus maze in males (left column) and females (right column). *with bracket $p<0.05$, significant main effect of prenatal treatment; * $p<0.05$, GD7 Alc vs. GD7 Con; male $n$ 's $=8-9$; female $n$ 's $=9-12$. 
A

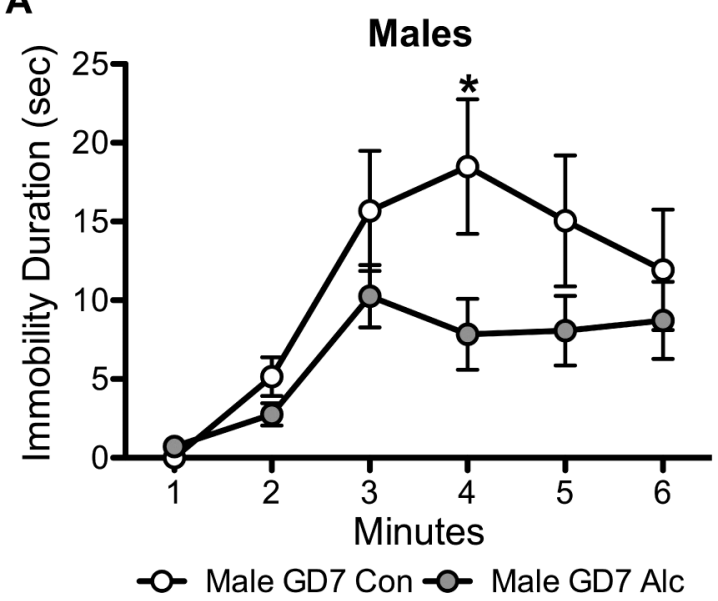

B

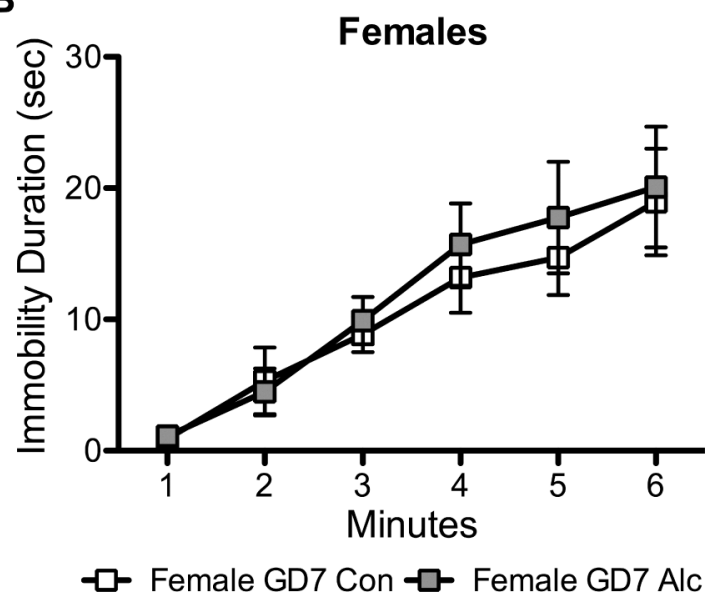

Figure 6. PAE affects depression-like behavior in a sexually dimorphic manner Immobility duration on the forced swim test was measured in males (A) and females (B) to test depression-like behavior. ${ }^{*} p<0.05$, GD7 Alc vs. GD7 Con; Male $n$ 's $=10-11$; Female $n$ 's $=13-15$. 